\title{
Smart multimedia learning of ICT: role and impact on language learners' writing fluency - YouTube online English learning resources as an example
}

\author{
Azzam Alobaid(10
}

Correspondence: azzam14_Ilh@jnu. ac.in

School of Languages, Literature and Culture Studies, New Delhi, India

\begin{abstract}
This work seeks to determine if and how much the smart learning environment of Information and Communications Technology (ICT) tools like YouTube can help improve learners' fluency of language use and expression in their daily written communication. This research highlights and takes advantage of the potential role and features of multimedia brought to the language learner by the ICT tools, taking YouTube online English learning resources as an example of this smart learning environment. This work hypothesizes that learners who engage with, expose themselves more to and leverage such online language materials could develop their fluency of daily language use and expression in writing over time. The findings of this research show that there is a statistically significant difference in some but not all aspects of the learners' writing fluency; basically, the accuracy and organization of ideas as qualitative dimensions of fluency improved after the actual exposure to YouTube over five months as long as factors like engagement, enhancement and intelligibility are provided by its multi-mediated input. However, other aspects of fluency in writing could develop slightly but with no statistically significant difference. Also, compared to other sources of language learning in the learners' environment, multimedia educational tools developed by ICT like the widely known platform YouTube can be more effective and thus strongly recommended equally for language learners and teachers where optimization of writing fluency is the target of learning. This paper is a work-in-progress that investigates the role and impact of smart learning environment of ICT multi-media on English language learners' fluency and accuracy of use and expression in speaking and writing.
\end{abstract}

Keywords: Smart learning, Multimedia materials, Input, ICT, YouTube, Writing, Fluency

\section{Introduction}

ICT in the field of education is the integration of various technologies of information and communication so as to leverage its capacity for the optimisation, enhancement and creating of a better learning environment and smoother learning process. A wealth of research in the literature showed the significant and positive impact on students'

(c) The Author(s). 2020 Open Access This article is licensed under a Creative Commons Attribution 4.0 International License, which permits use, sharing, adaptation, distribution and reproduction in any medium or format, as long as you give appropriate credit to the original author(s) and the source, provide a link to the Creative Commons licence, and indicate if changes were made. The images or other third party material in this article are included in the article's Creative Commons licence, unless indicated otherwise in a credit line to the material. If material is not included in the article's Creative Commons licence and your intended use is not permitted by statutory regulation or exceeds the permitted use, you will need to obtain permission directly from the copyright holder. To view a copy of this licence, visit http://creativecommons.org/licenses/by/4.0/. 
achievements through the increase in the use and exposure to ICT in education. Aoki (2010) in a report findings by the National Institute of Multimedia Education in Japan showed that "the students with continuous exposure to ICT technology through education demonstrated better 'knowledge', presentation skills, innovative capabilities, and were ready to take more efforts into learning as compared to their counterparts". Moreover, ICT has impacted multimedia learning of language with its attractive and interactive strengths to provide easy to reach multimedia language materials (MMLM); such MMLM are packaged with graphical, textual, animated, audio and video materials delivered to the end-user through wide variety of electronic devices, primarily via computers, smart boards and phones. ICT, whose implementation is intended to create smart learning environment- YouTube online English learning resources as an example of this smart learning environment, is synonymous with smart learning environments in this work. However, it would be useful to define smart learning environments although there is no completely agreed upon definition for them, yet they are often understood as an improvement of physical environments with novel technologies to provide a smart, interactive classroom with increased interactivity, personalized learning, efficient classroom management, and better student monitoring (Yesner, 2012, as cited in Libbrecht, Müller, \& Rebholz, 2015). Smart learning environments are related to ambient technologies, describing learning environments, which exploit new technologies and approaches, such as ubiquitous and mobile learning, to support people in their daily lives in a proactive yet unobtrusive way (Buchem and Pérez-Sanagustín, 2013; Mikulecký 2012, as cited in Libbrecht et al., 2015). The rational and significance for integrating ICT tools for creating smart learning environments in foreign/second language education lies in the fact that ICT multi-faceted features in the domain of language learning are many, especially those that can be beneficial for language learners like personalization, networking and interactivity, inclusiveness, richness of authentic and engaging input.

Personalization is one major facilitative characteristic of modern ICT in education also known as customization or individuality of choice of materials where a service or a product can be tailored to cater for specific individuals' or group's needs. Put differently, each student can now learn at his/her own pace and space and instructors can accommodate and cater for the individual needs and interests of learners. This feature can be hypothesized to enhance multi-media learning through the adjustment of a given language input that learners may be able to get more and clearer input and thus greater or more fluent output. More on personalization and the integrity of knowledge, Vaughan (1993) suggested that when the user or viewer of the project can adapt and control what and when these elements are delivered, it is interactive multimedia; more usefully, this interactive multimedia has become hypermedia providing learners with a structure of linked elements where now materials can be widely navigated, interacted with and exchanged. In this research ICT multimedia is employed as both interactive and hypermedia catalyst where a "structure of linked elements of knowledge" is bringing an array of MMLM to learners through their devices. Also, personalization includes the use of YouTube closed captions and its adjustable settings related to font size, color, opacity and the playback speed for learning and improving writing.

Networking and interactivity are the use of social networks in both private and academic life, for example YouTube. (Mukhaini, Al-Qayoudhi, \& Al-Badi, 2014) “These 
are tools used to enable users for social interaction. The use of social networks (SNs) complements and enhances teaching in traditional classrooms. For instance, YouTube, Facebook, wikis, and blogs provide a huge amount of material on a wide range of subjects. Students can, therefore, turn to any of these tools for further explanations or clarifications". This feature can be hypothesized to enhance the reception and production of input giving leaners a chance for language practice and active exposure.

Inclusiveness means that a wider diversity of people can make (easy) use of it. Rice (2011) Inherent in inclusive education is the notion that reform and improvements should not only focus on children with disabilities but on "whole school improvement in order to remove barriers that prevent learning for all students" (GeSCI, 2007, as cited in Rice, 2011). Inclusive schools can "accommodate all children regardless of their physical, intellectual, emotional, social, linguistic or other conditions" (Article 3, Salamanca Framework for Action). However, inclusive education is not a synonym for special needs education or integration techniques but an "an on-going process in an ever-evolving education system, focusing on those currently excluded from accessing education, as well as those who are in school but not learning" (UNESCO 2008). According to Rice (2011) "There is a wide variety of accessible ICTs currently available which can help overcome reduced functional capacity and enable communication, cognition and access to computers." This feature can mean welcoming and accommodating more learners through the potential outreaching and connecting with everyone.

Rich provider for authentic language input, context and culture as in the easy-to-get authentic input that is quantity- and quality-wise useful. Grzeszczyk (2016) noted that "CALL was expanding and introducing tools helped teachers to supply learners with more up-to-date, authentic, target-specific, and learner-oriented materials". According to Pun (2013) "using multimedia technology offers the students with more information than textbooks and helps them to be familiar with cultural backgrounds and real-life language materials, which can attract the students to learning". More on culture, Pun (2013) observed that "the learners, through the use of multimedia technology, will not only improve their listening ability, but also learn the culture of the target language; this brings about an information sharing opportunity among students and makes them actively participate in the class activities that help the students to learn the language more quickly and effectively". In terms of context, "the utilization of multimedia technology can create a context for the exchange of information among students and between teachers and students, emphasizing student engagement in authentic, meaningful interaction" (Warschauer \& Meskill, 2000, as cited in Pun, 2013) as in "using multimedia in English teaching/ learning can be an appropriate method to help students to get a sense of the sociocultural context in which the language is used" (Kramsch, 1999, as cited in Yang, 2008), "as well as raising students' language awareness under the framework of World Englishes" (Kunschak, 2004, McKay, 2002, as cited in Yang, 2008).

ICT can provide a whole raft of engaging multi-media materials as learners can be all the more free to choose and adjust their learning materials. A wealth of research has shown that "using social media as an educational tool can lead to increased student engagement motivating them to learn more (about) languages by way of audio, visual and animation support" Tarantino, McDonough, and Hua (2013). (See also Annetta, Minogue, Holmes, \& Cheng, 2009; Chen, Lambert, \& Guidry, 2010; Junco 2012; Patera, 
Draper, \& Naef, 2008). (Izquierdo, Simard, \& Garza, 2015) confirmed previously established research in education that ICT makes it easier for learners to access language materials, stressing an existing correlation between second language learning and the use of multi-media materials in a computer-enhanced language learning milieu showing an impact on learning behaviour with increased motivation. This said, ICT multi-media could be enriching for the learners' language experience as in helping learners write fluently (quantity- as well as quality-wise). This research underscores that the language used in this input can be taken as a model for the language learner. Thus, in addition to other previous and coming input possibly acquired by the learner, the new input could be in effect increasingly adding up to the learner's knowledge of language and developing their output to be more fluent.

With the above-mentioned plausible advantages of ICT in mind and that modern ICT technology like YouTube has impacted multimedia in education as far as it can be seen through a wide range of educational channels, it's worth questioning this impact from a desirable angle by language learners and instructors, which is the fluency of writing performance.

A far-reaching definition of fluency in writing that would suit the purpose of this study is based on a number of perspectives of fluency in the literature combined in a study by (Atasoy \& Temizkan, 2016) "the act of writing the maximum number of language units in a short period of time while also paying attention to accuracy, the coherent and consistent organization of ideas within the text, and the usage of words and sentences in a complex manner."

The focal point of this study is that, can learners of English make a progress in a better (in the sense of quality and quantity) communicative writing as long as the seemingly learning environment by way of multi-media technology of ICT cannot be more helpful as it is as facilitative as it sounds (both in terms of technical capabilities and language materials and content information possibilities) for learners of English in writing?

This study attempts to reach an understanding of what and how much, if any, can be developed of learners' written performance in terms of fluency given that they are to varying degrees exposed to and engaging with ICT multi-media during their learning process.

RQ. Can exposure to and engagement with ICT educational multimedia like YouTube have some effect on the development of learners' fluency of language use and expression in writing?

\section{Literature review}

This research examines the multimedia role of ICT in language learning as input provider of language materials, assuming that ICT YouTube technology as input provider and enhancer, and its impact on learners' development of fluency in writing. Therefore, it would be necessary to look into the relevant input theories of language learning and those of multimedia trying to connect the dots between them; the theories adopted in this research are the language learning theories of Comprehensible Input, Input and Interaction, Comprehensible Output, Input Enhancement, Noticing the Gap and the Multimedia Learning Theory.

The first and foremost stage of language acquisition assumed by Krashen and his proponents is the introduction of "comprehensible input" which is defined as "a language 
input which can be comprehended by listeners albeit not understanding all the words and structures in it. This input is described as one level above that of the learners if it can only just be understood" (British Council, 2020a, b). 'Comprehensible input' is the crucial and necessary ingredient for the acquisition of language supplied in a low anxiety situation, containing messages that students really want to hear. However essential to the language development, "comprehensible input is held to be a necessary, though not sufficient, condition for SLA" (Krashen, 1985; Long, 1983). Long's Input and Interaction Hypothesis (Long, 1985) argues for the significance of both input comprehension and modifications in order to facilitate language acquisition, i.e., through negotiated interaction of discourse structure and modified input. Following Krashen's comprehensible input hypothesis (1992, 1994), "Multi-media Instruction (MI) research has provided learners with rich exposure to the L2 in meaning-based tasks built upon different media features" (Plass \& Jones, 2005, as cited in Izquierdo et al., 2015).

According to Swain (2005), the output hypothesis "asserts that the act of producing language (speaking or writing) constitutes under certain circumstances, part of the process of second language learning" (Swain, 2005, p. 471, as cited in Pannell, Partsch, \& Fullver, 2017) and "that even without implicit or explicit feedback provided from an interlocuter about the learners' output, learners may still, on occasion, notice a gap in their own knowledge when they encounter a problem in trying to produce the L2" (Swain \& Lapkin, 1995).

Input enhancement, Smith (1991) examines the concept of "consciousness raising' in second language learning, i.e., how certain features of language input become salient to learners suggesting different ways for making input salient and different ways in which such salience may affect the learner's knowledge and performance in language learning". Relating to the concept of consciousness raising is what is now termed in neurolinguistics as metacognitive awareness. Just as it is essential to effective learning, metacognition is an important part of successful technology adoption (Gurbin, 2015).

The noticing hypothesis (Schmidt, 1990, 2001, as cited in Schmidt, 2010) argues that "input does not become intake for language learning unless it is noticed, that is, consciously registered".

Mayer (2009) defines a "multimedia environment as one in which material is presented in more than one format - such as in words and pictures" where according to his "multimedia principle", Mayer (2002) premises that "people can learn more deeply when they receive an explanation in words and pictures rather than words alone". In the same vein, "according to the sensory modalities view, in his perspective, multimedia means that two or more sensory systems in the learner are involved. It focuses on the sensory receptors the learner uses to perceive the incoming material - such as the eyes and the ears". In this respect, the signalling principle of multimedia states that students engage in "deeper learning when key steps in the narration are signalled rather than non-signalled" (Mayer, 2005). Signals give cues to the learners about what words and pictures to notice and enables their organisation. This means that linguistic elements need to be linked to some visual stimuli so as to assist learners' storage of the new linguistics elements in their long-term memory (Matus, 2018).

In relation to these multimedia theories, a number of multimedia technology studies were conducted in the field of language learning focusing on different language aspects and different multimedia applications and their potential impacts and facilitative 
features. For example, the multi-media effect of captions or subtitles inclusion whilst watching films dealt with issues like the listening comprehension improvement and vocabulary acquisition. (Yoshino, Kano, \& Akahori, 2000) examined the listening comprehension of Japanese EFL students and found that foreign subtitles inclusion can be "helpful but native-language subtitles provide no benefit or less benefit" in this regard. (Mitterer \& McQueen, 2009) supported the previous studies that second language learners can boost their listening ability when watching films with "foreign-language subtitles as this can improve repetition of both previously heard and new words, the latter demonstrating lexically-guided retuning of perception. While native-language subtitles can help only recognition of previously heard words but harm recognition of new words". In terms of vocabulary acquisition, in their study (Winke, Gass, \& Sydorenko, 2010) mentioned "a number of observations about the use of captions, confirming previous research that captions are beneficial because they result in greater depth of processing by focusing attention, reinforce the acquisition of vocabulary through multiple modalities, and allow learners to determine meaning through the unpacking of language chunks". Xiao (2007) conducted a study on the effect of the use or interaction with native speakers through video conferencing as a multimedia for oral practice of speaking in English on learners' oral improvement of fluency, accuracy and complexity. He found "a significant improvement in fluency, a slightly significant improvement in accuracy, but no improvement in complexity for the L2 learners" as a result of this kind of exposure to English to interact with native speakers.

The potential of using ICT multimedia with its features of personalization, networking, inclusiveness, richness of engaging input, context and culture like YouTube for language learning and its impact on other aspects like the fluency of use and expression of writing, however, has not been sufficiently investigated. This research is mainly interested in the role of the foreign language subtitled multimedia (like YouTube) effect on learner' improvement of writing fluency. In this research, "multimedia" means the availability of both speech and text as implied by the sensory modalities view of multimedia contrasted with mono-media as having either of them, i.e., speech/ text, Mayer (2009).

To connect the dots, this work proposes the use of ICT as a multimedia source of comprehensible input which is hypothesized to lend itself to help learners producing comprehensible output, i.e., or more fluent use and expression of language in writing; this is hypothesized to be achieved first, as 'learners consciously by themselves or made conscious by the teacher to notice their gap(s), (especially in terms of gaps related to accuracy of language use), in the provided input-what becomes intake for learning' as implied in the Noticing the Gap Hypothesis; second, through 'negotiated interaction (with the teacher or other learners using some given multi-media material in question) and modified input' as implied by Long's Input and Interaction Hypothesis (Long, 1985). One effective way to let input noticing and negotiating happen is through the use of the ICT personalization and networking and interactivity features, respectively; "the process by which language input becomes salient to learners" as indicated by the Input Enhancement Hypothesis. These workings entailed from these language learning theories collectively can arguably be practically put into action within the Sensory Modalities View of Multimedia framework when the sensory receptors of the eyes and the ears of the learner are used to perceive the incoming material of text and speech respectively in the ICT leaning environment. 
Our multimedia approach takes to the full a great advantage of the multiple personalization features provided by the ICT technology available in this research example, i.e., YouTube, to make a given input as much salient or comprehensible and reproduceable as needed; such features are mainly the optional text aligned with the speech, with care given to correct spelling, placement of punctuation marks and capitalization; font size, colour and opacity; and the playback speed. Such features are considered as highly significant and facilitative for both comprehending the meaning and noticing the form(s) of the language presented in a given episode on such YouTube channels. Familiarizing learners with or controlling these features in proportion to the learners' needs can perhaps better benefit learners navigate their learning of the language in hand and make it more accurate and fluent; that is to say, understand more and faster meaning and notice more and clearer forms, so much so that their knowledge of the language forms would not only be increasingly informed and enriched but also the number of language errors be it grammatical (omission, addition, misordering), lexical (misinformation, misspelling, informality) or mechanical (punctuation, capitalization) would be reduced (for the categorization of error types and analysis used in this research this work refers to the taxonomy by (Dulay, H. et al., 1982, as cited in Ellis \& Barkhuizen, 2005) and the work of Ferdouse (2013). From the Input and Interaction view such learning is supposed to happen due to the learners being exposed to and engaged with this multi-mediated authentic input which can be set as a model to acquire or learn language from.

Having the plausible advantages of ICT in mind supported by research in the literature, this work attempts to first activate and encourage the use of YouTube as an example of ICT in class as well as out of class and then check on its likely impact to find answers to questions like what and how much linguistic input, if any, learners get through ICT as far as fluency in communicative writing in English is concerned. Our approach explores, in terms of exposure time range and engagement degree, the various potential language learning resources in the learning environment of this sample group, including the ICT YouTube as one of these sources; then, we correlate these sources, which are deemed as explanatory variables in this study, with the learners' actual performance of communicative writing fluency. This work suggests the BBC SixMinute English YouTube Channel as a case study.

This study selected and relied on exposure time range and engagement rate as factors or indicators of learning due to their huge popularity in literature as significantly influential drivers of learning foreign/ second languages (For the significance of exposure time see Benson, 2001; Ellis, 2002; Krashen, Long, \& Scarcella, 1979; Peregoy \& Boyle, 2005. For the significance of engagement see Astin, 1984, 1993; Benek-Rivera \& Matthews, 2004; Bertin, Grave, \& Narcy-Combes, 2010; Sarason \& Banbury, 2004). Early studies defined student engagement primarily by observable behaviors such as participation and time on task (Brophy, 1983; Natriello, 1984). Researchers have also incorporated emotional or affective aspects into their conceptualization of engagement (Connell, 1990; Finn, 1989). It can be understood from these definitions that engagement include feelings of belonging, enjoyment, and attachment, which is how this study defined the engagement for its analysis. Time range of exposure was defined for this study as "the contact that the learner has with the language that they are trying to learn, either generally or with specific language points". (British Council, 2020a, 2020b). 


\section{Research methods}

This research is a longitudinal study investigated patterns within time-series data. The performance of a single group of participants was measured both before and after the experimental treatment. It was conducted over a period of five months at the Iraqi school in New Delhi. It's a co-education schooling system where 14 learners, who showed interest in this project, were randomly selected. The range of population sample age was $12-15$ years (five boys and nine girls, i.e., $35 \%$ and $65 \%$ respectively). The proficiency level of the language learners was estimated to be pre-intermediate and above as their average formal semester evaluation scores of English subject showed. The medium of instruction at school is Arabic except for English classes it's Englishbased most of the time. English for the participants is second as it has to be used outside the classroom where the bigger context is Delhi where English is 'for most of the population has only ever been a second language' (Robinson, 2019). At the beginning, participants were explained the general framework of the study and given freedom to entirely choose for themselves the content out of the suggested YouTube channel for discussion and writing about for every class. Participants were met three days a week and YouTube was at the heart of the meeting to interact with its content in a watchtake notes-discuss modality using the necessary technological accessories for that matter like an overhead projector, sound amplifier and good internet connectivity for browsing and streaming a given program, in this case the BBC Six-Minute English YouTube channel. It is the program suggested by the researcher as it's only a sixminute, free of charge weekly show presented in English using the British English. It's designed and broadcasted by the BBC for intermediate level classes. The rationale behind introducing this channel on YouTube as a tool in ELT classes is that it matches the learners' overall proficiency level, and these videos use General English-the dayto-day English used exclusively in people's lives presented in a casual and conversational style that helps learners learn and practice authentic useful English language for everyday situations as in saying, writing or doing something using English.

\section{Pedagogical scenario and task design}

At home

At the end of every English class learners were suggested three videos by the instructor (the titles were supposed to be interesting and new to them), and they had to vote (each according to the topic s/he liked) for one of them, and the majority would win for that matter. This new video of BBC six-minute English would be the subject matter for next class. At home, learners start watching to explore and understand the theme on their own. After watching it as many times as needed, learners were asked to write a summary and add their comments about the topic discussed in a given video of this channel. Also, they were encouraged to note down any inquires or doubts about the topic and bring that to class for open discussion. Learners were strongly advised and encouraged to refer to and use the closed captions and its adjustable settings like font size and colour in a given video to check for themselves on the right meaning of the topic/ some sentence or to check (problematic/ unfamiliar) grammatical forms/ vocabulary, word choice, spelling, punctuations, abbreviations, or capitalization. Learners were to do this every time they were given a writing task. 


\section{At school}

At the start of the writing lesson, the same video with the subtitle turned on was watched by the whole class once again. Then, learners were asked to read out their written summaries and discuss with the class the general idea of the introduced topic. Also, the teacher would basically use the subtitle and its adjustable related settings of font size and colour for their signalling effect (Mayer, 2009), which will be projected on the board, to refer to and discuss a particular language point/ inquiry. These language points/ inquiries were mainly those raised directly by the learners themselves, or indirectly when errors were noticed in their writing or even the teacher can pinpoint some language points whenever found noteworthy, relevant and enriching for the learners' writing. Moreover, learners were encouraged to refer back to the subtitle as a reference point at any time they need to check for themselves and with each other on the right meaning of the topic/ some sentence and check the accuracy of word choice, morphological/ grammatical structures, abbreviations, spelling, punctuations or capitalization.

\section{Data collection}

In order to elicit the data from the current population sample, this research adopts a strategy of triangulation through two methods.

Two IELTS-based communicative writing tasks were conducted for the baseline and other two different IELTS writing tasks were conducted as an end line. The tests were given to learners before and after the introduction and integration of the suggested YouTube Channel, BBC Six-Minute English YouTube Channel so as to record their actual writing fluency progress, taking the IELTS standards for the test administration into consideration. Learners are, thus, examined on two communicative tasks each time rather than a single one and the total of two is given as a single line of reference each time for evaluation. This is considered to be more representative of the learners overall communicative competence. The findings of these tests provided the data required to help answering the main research question of this study.

Nonetheless, there is a wide range of likely factors and resources (also known as confounding variables) of English language learning that may co-exist in the learning environment of this research population and hence may impact to varying degrees the improvement of this population's targeted variable of fluency of writing. Also, this work can only focus on one of these many resources and is mainly interested in the role and impact of ICT multi-media like YouTube as a language learning tool. Therefore, to be able to overcome this challenge and make a valid judgment about other variables which might be playing a role along with the possible YouTube role in the possible development of learners' writing fluency for this sample group, a quantitative and qualitative online questionnaire was developed according to the specific aims and context of this study, measuring specific potential resources of English language learning in terms of the learners' daily time range of active exposure to and learning engagement rate with them. The percentages drawn from the population sample responses through the online questionnaire were employed to identify several factors/ independent variables in terms of exposure time and engagement rates with the potential learning sources of English language learning; that would be correlated with the actual linguistic progress learners may make. These percentages are namely the likely potential media or contexts 
of language learning favoured by learners (e.g. reading and/or listening), preferred mode of exposure (online, offline), modality (text and/or speech), the language skill(s) involved, the type of input material exposed to (as in songs, films, video games, (audio) books). This self-report questionnaire was administered at the end of the five months. The learners' responses from the survey items were used in the quantitative and qualitative analyses to answer the main research question mentioned above. This questionnaire which was a combination of closed-ended and Likert questions (35 items in total) covered three main areas. First, the participants' English writing learning experience of both the online and offline English learning resource(s) including YouTube with regards to their engagement rate with and daily time range of exposure to each of these resources (Qs. 4-29 see Appendix A for the questionnaire items related to this area). for the questionnaire items related to this area). Second, the participants' English writing learning experience with YouTube in particular as an ICT tool for creating the intended smart learning environment with respect to its features of personalization, networking and interactivity, inclusiveness and as a resource for rich language input and engaging multi-media materials for learning and improving your English writing (Qs. 30-33 see Table 8 for the questionnaire items related to this area). Third, learners' personal and contextual perspectives on the affordances of YouTube videos and how they thought YouTube videos made learning and improving writing easy and interesting according to their experience (Qs. 34 \& 35 see Tables $9 \& 10$ for the questionnaire items related to this area).

\section{Data analysis}

The data analysis included both quantitative and qualitative methods. The quantitative methods used in this study were Matched-pairs t-test, Pearson's correlation, Simple linear regression and frequency distributions. A matched-pairs t-test was used as it is appropriate for a repeated measure design where the same subjects are evaluated under two different conditions such as the case in this study. Pearson's Correlation was used to explore the relationship between the learners' writing fluency progress (as the dependent variables for correlation; the data for these variables were elicited from the T. test findings after the integration of YouTube) and the participants' English writing learning day-to-day experience with some potential online/ offline mono-medium and multimedia learning materials/ environments, including YouTube media with regards to the participants' engagement rate with and daily time range of exposure to each of these resources. (as the independent variables for correlation; the data for these variables were elicited from the respective questionnaire items Qs. 4-29). Simple linear Regression, focusing primarily on the Likert items which showed a linear relationship, was conducted to identify the variation of the engagement rate with and time range of exposure to YouTube as predictor variables on the writing fluency metrics. Frequency Distributions were used to determine the percentages of learners' active use of ICT with regards to its features of personalization, networking and interactivity, inclusiveness and as a resource for rich language input and engaging multi-media materials for learning and improving English writing (the data for frequency distribution were elicited from the questionnaire items Qs. 30-33). 
In terms of the qualitative method, a simple content analysis consisting of two closed-ended questions was performed. Learners were asked to choose how they thought YouTube videos made learning and improving writing easy and interesting according to their experience. The answers list (for these two questions) learners were to choose from are widely mentioned in the literature of learning writing (except for those relating to closed captions which were investigated in this study) and in line with the research questions of this study (the data for content analysis were elicited from the questionnaire items Qs. 34-35).

\section{Coding the data}

As for the test findings, all the participants' responses ( $n$. 14) were analysed in terms of writing accuracy objectively using the taxonomy of errors by Dulay, H. et al. (1982) cited in Ellis and Barkhuizen (2005) and then coded based on the work by Oshima and Hogue (1997) and developed in the work of Ferdouse (2013). Each writing task was rated twice and the inter-rater reliability of the ratings for the 56 writing tasks used in this study was 0.87 . Inter-rater reliability rates between 0.75 and 0.9 are good, Koo and Li (2016). Also, this research used seven metrics or dimensions of various foci of writing fluency of quantitative and qualitative nature widely accepted in the literature as indicators of fluency development (see Ellis, R., 1990; Lu, X., 2010, 2011; Lu, X., \& Ai, H, 2015; Wolfe-Quintero, K., et al., 1998; Vaezi \& Kafshgar, 2012; Fellner and Apple, 2009; Van Gelderen, A., \& Oostdam, R., 2005); these were used as the dependent variables of this study. These dependent variables are of quantity and quality nature. This study used only one quantitative dimension of writing fluency, namely the writing rate which is measured by the number of syllables written per minute in a text. The qualitative dimensions of writing fluency were the number of error-free T. units per text as a sub-dimension of accuracy dimension; lexical diversity (measured by different number of words/total number of words $\times 100$ ) and lexical density (measured by the number of content words/total number of words $\times 100$ ) as sub-dimensions of lexical complexity dimension; mean length of T. unit and number of clauses per T.unit as subdimensions of syntactic complexity dimension, and organization of ideas which is measured by the overall coherence \& cohesion of ideas and task achievement. It should be mentioned that the author used online automatic softwares to conduct the required writing fluency analyses for this study (see Web-based L2 Syntactic Complexity Analyzer by Ai, H., (n.d.), Ai, H., \& Lu, X. 2013; Analyze My Writing (n.d.); TAASSC, see Kyle, K. 2016; Text Inspector, (n.d.)). These softwares are cited in the reference list with the respective URLs.

As for the questionnaire findings, all the participants' responses (n. 14) were downloaded to a Microsoft Excel sheet and subsequently exported to SPSS version 21.0. With respect to the engagement rate, it was measured on a five-point Likert scale where 1-point was defined as very low engagement and 5-points as very high engagement. As for the exposure time range, it was defined by the number of hours spent in a day using each of these resources for learning English and measured on a five-point Likert scale. Time range of exposure was coded as 0 , one hour as 1 , two hours as 2 , three hours as 3 and more than $3 \mathrm{~h}$ as 4 . 


\section{Results}

Quantitative results

Matched-pairs t-test

In order to be able to check and account for the difference with regards to the baseline compared to the end line datasets of learners' writing performance objectively, the statistical T. test was used. The means differences between these datasets showed to various degrees some improvement across all the dependent variables set in this work except for the lexical density variable as shown by the means differences in the fluency gain level of writing post the integration of YouTube as an ICT tool for learning and improving writing (Table 1) (Details on each variable will be discussed below). Most statistical analyses would use an alpha of 0.05 as the cut-off for the level of significance. If it is found that the $p$ value $<0.05$, then the null hypothesis that there is no difference between the means before and after the study can be rejected. The following null hypothesis $\left(\mathrm{H}_{\mathrm{o}}\right)$ set in this work and its alternative hypothesis $\left(\mathrm{H}_{\mathrm{a}}\right)$ are as follows:

$\mathrm{H}_{\mathrm{o}}=$ exposure to and engagement with ICT educational multimedia like YouTube has no effect on the development of learners' fluency of language use and expression in writing.

$\mathrm{H}_{\mathrm{a}}$ = exposure to and engagement with ICT educational multimedia like YouTube has an effect on the development of learners' fluency of language use and expression in writing.

The following are the $T$. test results (see Table 1) for the quantitative and qualitative writing fluency dimensions.

\section{Quantitative dimension}

Writing rate The results from the pre-test $(M=5.72, S D=2.09)$ and post-test $(M=$ $6.19, S D=1.66)$ writing tasks showed a slight improvement in the learners' writing fluency in terms of writing rate after the exposure to the suggested ICT tool, $t(14)=$ $1.353, p=.199$.

\section{Qualitative dimension}

Number of error-free $T$. units per text The results from the pre-test $(M=1.57, \mathrm{SD}=$ $2.24)$ and post-test $(\mathrm{M}=7.21, \mathrm{SD}=6.14)$ writing tasks showed good improvement in writing fluency in terms of the number of error-free T.units per text after the exposure to the suggested ICT tool, $t(14)=4.623, p<.001$.

Lexical diversity subdimension of Lexical complexity The results from the pre-test $(M=52.54, S D=19.96)$ and post-test $(M=54.86, S D=15.11)$ writing tasks showed a slight improvement in writing fluency in terms of lexical diversity after the exposure to the suggested ICT tool, $t(14)=0.526, p=.608$.

Lexical density subdimension of Lexical complexity The results from the pre-test $(M=47.25, S D=4.59)$ and post-test $(M=44.41, S D=2.75)$ writing tasks showed no 


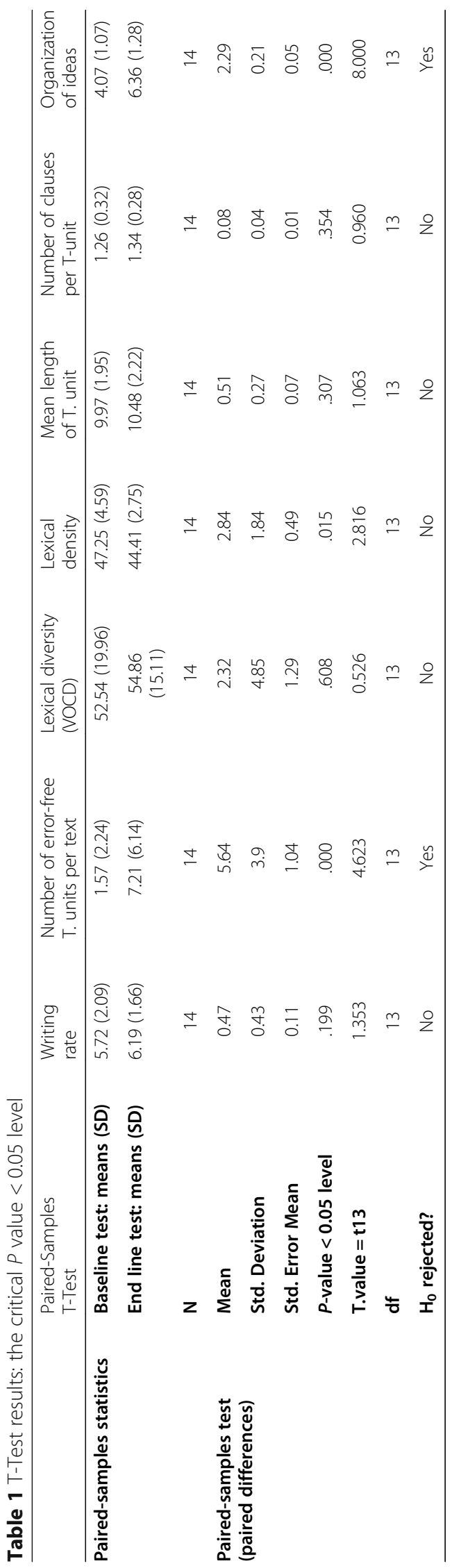


improvement in writing fluency in terms of lexical density after the exposure to the suggested ICT tool, $t(14)=2.816, p=.015$.

Mean length of T. unit subdimension of Syntactic complexity The results from the pre-test $(M=9.97, S D=1.95)$ and post-test $(M=10.48, S D=2.22)$ writing tasks showed a slight improvement in writing fluency in terms of syntactic complexity after the exposure to the suggested ICT tool, $t(14)=1.063, p=.307$.

Number of clauses per $\mathbf{T}$. unit subdimension of Syntactic complexity The results from the pre-test $(M=1.26, S D=0.32)$ and post-test $(M=1.34, S D=0.28)$ writing tasks showed a slight improvement in writing fluency in terms of syntactic complexity after the exposure to the suggested ICT tool, $t(14)=0.960, p=.354$.

Organization of ideas The results from the pre-test $(M=4.07, S D=1.07)$ and posttest $(M=6.36, S D=1.28)$ writing tasks showed a slight improvement in writing fluency in terms of the number of error-free T.units per text, $t(14)=8.000, p<.001$.

To summarize the $\mathrm{T}$. test results, all dependent variables (except for the lexical density variable) set as indicators of fluency of writing in this study have to various degrees shown some improvement after five months of focused exposure to YouTube as indicated by their means differences in the T. test results. However, only two of them were statistically significant, namely, the number of error-free $T$. units per text and organization of ideas.

\section{Correlation coefficient results (the critical value approach)}

Pearson's Correlation was used to explore the strength and the direction of the relationship between the learners' writing fluency which was based on the T. test findings after the integration of YouTube and the participants' English writing learning day-today experience with some potential online/ offline mono-medium and multimedia learning materials, including YouTube media with regards to the participants' engagement rate with and daily time range of exposure to each of these resources. With regards to the strength of association between variables, the critical value for Pearson's $|\mathrm{r}|$ was set at the value of $0.05=0.532$ (as a level of significance for a two-tailed test given by Pearson table of critical values) with a degree of freedom $\mathrm{df}=\mathrm{N}-2, \mathrm{df}=14-2=$ 12. So, any correlation coefficient value falling below the 0.532 was considered insignificant and any correlation coefficient value above the 0.532 was seen as significant (only the significant correlation coefficient values were highlighted in the tables below), where the higher the $r$ value or closer to $|+1 /-1|$ the stronger the correlation is between any two variables.

As for the direction (i.e., negative $=-\mathrm{ve} /$ positive $=+\mathrm{ve}$ ) of the relationship between variables, all seven dependent variables in each of the correlation tables below should be positively correlated with the independent variables as these particular dependent variables were dealing with factors where higher rates or values reflect higher or better outcome on the part of the learners so that the higher the value of each correlation coefficient means the better the performance or the more fluent the writing is. No negative correlation between any of these variables should be predicted for this work. 
The critical value for Pearson's $|\mathrm{r}|$ was set at the level of $0.05=0.532$.

The results of the correlation analysis were broadly divided into two main categories — online Vs. offline learning.

Online learning The correlation coefficient results of the learners' engagement rate with the respective online mono-medium and multimedia learning sources showed various values of which the majority were insignificant in terms of correlation, especially in the mono-medium learning environment. Nevertheless, the significant correlation values in terms of both strength and direction were those in the multimedia environment of YouTube, video games and audio books. (see Table 2). These significant correlations were as follows:

- One strong +ve correlation $(\mathrm{r}=.763)$ for the multimedia provided by video games;

- One strong +ve correlation $(r=.606)$ for the multimedia provided by films;

- One moderate +ve correlation $(\mathrm{r}=.575)$ for the multimedia provided by audio books; and

- One moderate +ve correlation $(\mathrm{r}=.598)$, two strong +ve correlations $(\mathrm{r}=.606, .732)$ and two very strong +ve correlations $(r=.867, .844)$ for the multimedia provided by the YouTube.

These results showed that the correlations of learners' engagement are significant on the multimedia side rather than the mono-medium one. However, more specifically there are more significant and stronger correlation values with the multimedia by YouTube against most of the set metrics of writing fluency than the correlation values with multimedia by video games, films or audio books.

This may indicate that learners were engaging with the multi-media materials by YouTube more and to a greater extent than the rest of other learning sources in their online learning environment and that the multi-media materials are preferred over the mono-medium materials.

The correlation coefficient results of the learners' time range of exposure to the respective online mono-medium and multimedia learning sources showed that there were insignificant correlations from the majority of the resources

Table 2 Pearson's correlation coefficient: Engagement Rate (Online learning)

\begin{tabular}{|c|c|c|c|c|c|c|c|}
\hline \multirow[t]{2}{*}{ Engagement Rate } & \multicolumn{2}{|c|}{$\begin{array}{l}\text { Mono-medium (text / } \\
\text { speech) }\end{array}$} & \multicolumn{5}{|c|}{ Multimedia (text \& speech) } \\
\hline & $\begin{array}{l}\text { Reading } \\
\text { (books) }\end{array}$ & $\begin{array}{l}\text { Listening } \\
\text { (songs) }\end{array}$ & $\begin{array}{l}\text { YouTube BBC 6- } \\
\text { Minute English }\end{array}$ & $\begin{array}{l}\text { Video } \\
\text { games }\end{array}$ & Songs & Films & $\begin{array}{l}\text { Audio } \\
\text { books }\end{array}$ \\
\hline Writing rate & -0.039 & -0.068 & 0.606 & -0.436 & 0.333 & 0.327 & 0.061 \\
\hline No. of error-free T. units per text & -0.341 & 0.226 & 0.867 & -0.334 & 0.062 & 0.606 & 0.575 \\
\hline Lexical diversity (VOCD) & -0.783 & 0.204 & 0.844 & -0.150 & 0.310 & 0.136 & 0.453 \\
\hline Lexical density & -0.250 & -0.287 & 0.448 & 0.763 & -0.371 & -0.498 & 0.184 \\
\hline Mean length of T.unit & -0.182 & 0.039 & 0.409 & -0.317 & 0.103 & 0.139 & -0.072 \\
\hline Number of clauses per T-unit & -0.524 & 0.047 & 0.598 & -0.244 & 0.125 & 0.161 & 0.233 \\
\hline Organization of ideas & -0.485 & 0.017 & 0.732 & -0.053 & 0.000 & 0.458 & 0.472 \\
\hline
\end{tabular}


Table 3 Pearson's correlation coefficient: Time Range of Exposure (Online learning)

\begin{tabular}{|c|c|c|c|c|c|c|c|}
\hline \multirow[t]{2}{*}{ Time Range of Exposure } & \multicolumn{2}{|c|}{$\begin{array}{l}\text { Mono-medium (text / } \\
\text { speech) }\end{array}$} & \multicolumn{5}{|c|}{ Multimedia (text \& speech) } \\
\hline & $\begin{array}{l}\text { Reading } \\
\text { (books) }\end{array}$ & $\begin{array}{l}\text { Listening } \\
\text { (songs) }\end{array}$ & $\begin{array}{l}\text { YouTube BBC 6- } \\
\text { Minute English }\end{array}$ & $\begin{array}{l}\text { Video } \\
\text { games }\end{array}$ & Songs & Films & $\begin{array}{l}\text { Audio } \\
\text { books }\end{array}$ \\
\hline Writing rate & -0.096 & 0.299 & 0.514 & -0.390 & 0.149 & -0.145 & 0.018 \\
\hline No. of error-free T.units per text & 0.089 & 0.014 & 0.783 & -0.317 & 0.048 & -0.393 & 0.394 \\
\hline Lexical diversity (VOCD) & -0.002 & 0.375 & 0.734 & -0.100 & 0.127 & 0.131 & 0.332 \\
\hline Lexical density & 0.081 & -0.226 & 0.426 & 0.699 & 0.113 & 0.395 & 0.125 \\
\hline Mean length of T.unit & -0.310 & 0.367 & 0.494 & -0.333 & 0.247 & -0.225 & -0.300 \\
\hline Number of clauses per T-unit & -0.111 & 0.198 & 0.767 & -0.279 & 0.126 & -0.037 & -0.114 \\
\hline Organization of ideas & 0.213 & 0.215 & 0.761 & -0.104 & 0.010 & 0.010 & 0.211 \\
\hline
\end{tabular}

except for the YouTube and video games results (see Table 3) which were as follows:

- One strong +ve correlation $(\mathrm{r}=.699)$ for the multimedia provided by video games;

- Four strong +ve correlations $(r=.783, .734, .767, .761)$ for the multimedia provided by YouTube.

The results of time range of exposure (Table 3) seem to conform with the above results of engagement rate (Table 2) that while learners were giving far greater amounts of their learning time and attention in the multimedia leaning environment, they gave little or no time and attention in the mono-medium learning environment. This may suggest that learners were more inclined towards the multi-media learning environment than the mono-medium environment for learning and improving writing online; more specifically, when compared to other online multi-media learning sources, YouTube as multimedia learning tool cum environment was preferred over other learning multimedia in as far as learning and improving writing is concerned.

Offline learning The correlation coefficient results of the learners' engagement rate with the respective offline mono-medium and multimedia learning sources showed insignificant correlation values across all the variables except for one strong +ve correlation value for video games $(r=.763)$. (see Table 4$)$.

Table 4 Pearson's correlation coefficient: Engagement Rate (Offline learning)

\begin{tabular}{|c|c|c|c|c|c|c|}
\hline \multirow[t]{2}{*}{ Engagement Rate } & \multicolumn{3}{|c|}{ Mono-medium (text / speech) } & \multicolumn{3}{|c|}{ Multimedia (text \& speech) } \\
\hline & $\begin{array}{l}\text { Reading } \\
\text { (books) }\end{array}$ & $\begin{array}{l}\text { Listening } \\
\text { (songs) }\end{array}$ & $\begin{array}{l}\text { Video } \\
\text { games }\end{array}$ & $\begin{array}{l}\text { Formal } \\
\text { schooling }\end{array}$ & Films & $\begin{array}{l}\text { Audio } \\
\text { books }\end{array}$ \\
\hline Writing rate & -0.011 & 0.291 & -0.436 & 0.223 & 0.171 & 0.329 \\
\hline No. of error-free T.units per text & -0.178 & -0.094 & -0.334 & -0.049 & 0.219 & -0.013 \\
\hline Lexical diversity (VOCD) & 0.110 & -0.144 & -0.150 & 0.137 & 0.086 & 0.022 \\
\hline Lexical density & 0.008 & -0.282 & 0.763 & 0.182 & -0.373 & -0.331 \\
\hline Mean length of T.unit & 0.342 & 0.003 & -0.317 & 0.382 & 0.217 & 0.249 \\
\hline Number of clauses per T-unit & 0.009 & -0.190 & -0.244 & 0.134 & -0.078 & -0.006 \\
\hline Organization of ideas & -0.337 & -0.217 & -0.053 & 0.337 & 0.018 & -0.125 \\
\hline
\end{tabular}


These insignificant results may suggest that learners were not engaging their learning in the offline mono-medium and multimedia learning environments at all.

The correlation coefficient results of the learners' time range of exposure with the respective offline mono-medium and multimedia learning sources showed that there are insignificant correlations from most of the resources in terms of time of exposure except for the reading of books variable results which are as follows: (see Table 5)

- Two strong +ve correlations $(\mathrm{r}=.713, .774)$ and one very strong +ve correlation $(\mathrm{r}=.842)$.

This may suggest that learners were giving a good deal of their learning time to reading books in the offline mono-medium leaning environment.

To summarize the correlation results of the above mentioned potential online/ offline mono-medium and multimedia learning materials/ environments, including YouTube media with regards to the participants' engagement rate with and daily time range of exposure to each of these resources, it can be concluded with statistical evidence that there is a strong positive correlation between the writing fluency performance shown by this group of learners and multi-media (rather than mono-medium) learning environments found online (rather than offline) such as the suggested ICT YouTube tool, where text can be optionally available along with speech. Moreover, multi-media materials/ environments like YouTube as an example are more engaging compared to other language learning sources and hence learners were spending much more time using them which could have led to a more effective learning in their writing fluency; this may suggest the usefulness of ICT tools like YouTube as an example which have resulted in a more fluent use of written language in some (but not all) dimensions of writing fluency over time as learners could with the help of ICT handle their learning efficiently. However, from a statistical perspective, it is important to stress that correlation between any two variables does not mean causation but only that there is a relationship between them such as the kind of positive linear relationship which exists between engagement rate and time range of exposure in relation to the writing fluency metrics of this study (see Fig. 1. a \& b). These correlational findings which revealed such positive linkages among the data set encouraged the employment of the following regression analysis.

Table 5 Pearson's correlation coefficient: Time Range of Exposure (Offline learning)

\begin{tabular}{|c|c|c|c|c|c|c|}
\hline \multirow[t]{2}{*}{ Time Range of Exposure } & \multicolumn{3}{|c|}{ Mono-medium (text / speech) } & \multicolumn{3}{|c|}{ Multimedia (text \& speech) } \\
\hline & $\begin{array}{l}\text { Reading } \\
\text { (books) }\end{array}$ & $\begin{array}{l}\text { Listening } \\
\text { (songs) }\end{array}$ & $\begin{array}{l}\text { Video } \\
\text { games }\end{array}$ & $\begin{array}{l}\text { Formal } \\
\text { schooling }\end{array}$ & Films & $\begin{array}{l}\text { Audio } \\
\text { books }\end{array}$ \\
\hline Writing rate & 0.501 & 0.112 & -0.299 & 0.108 & 0.037 & -0.156 \\
\hline No. of error-free T.units per text & 0.713 & -0.242 & -0.338 & 0.197 & 0.230 & -0.112 \\
\hline Lexical diversity (VOCD) & 0.526 & -0.217 & -0.466 & 0.199 & 0.298 & -0.222 \\
\hline Lexical density & -0.485 & -0.193 & 0.422 & 0.290 & 0.232 & 0.210 \\
\hline Mean length of T.unit & 0.774 & -0.138 & 0.029 & -0.029 & -0.222 & -0.418 \\
\hline Number of clauses per T-unit & 0.842 & -0.155 & -0.174 & 0.050 & -0.218 & -0.249 \\
\hline Organization of ideas & 0.381 & -0.077 & -0.080 & 0.306 & 0.104 & -0.085 \\
\hline
\end{tabular}




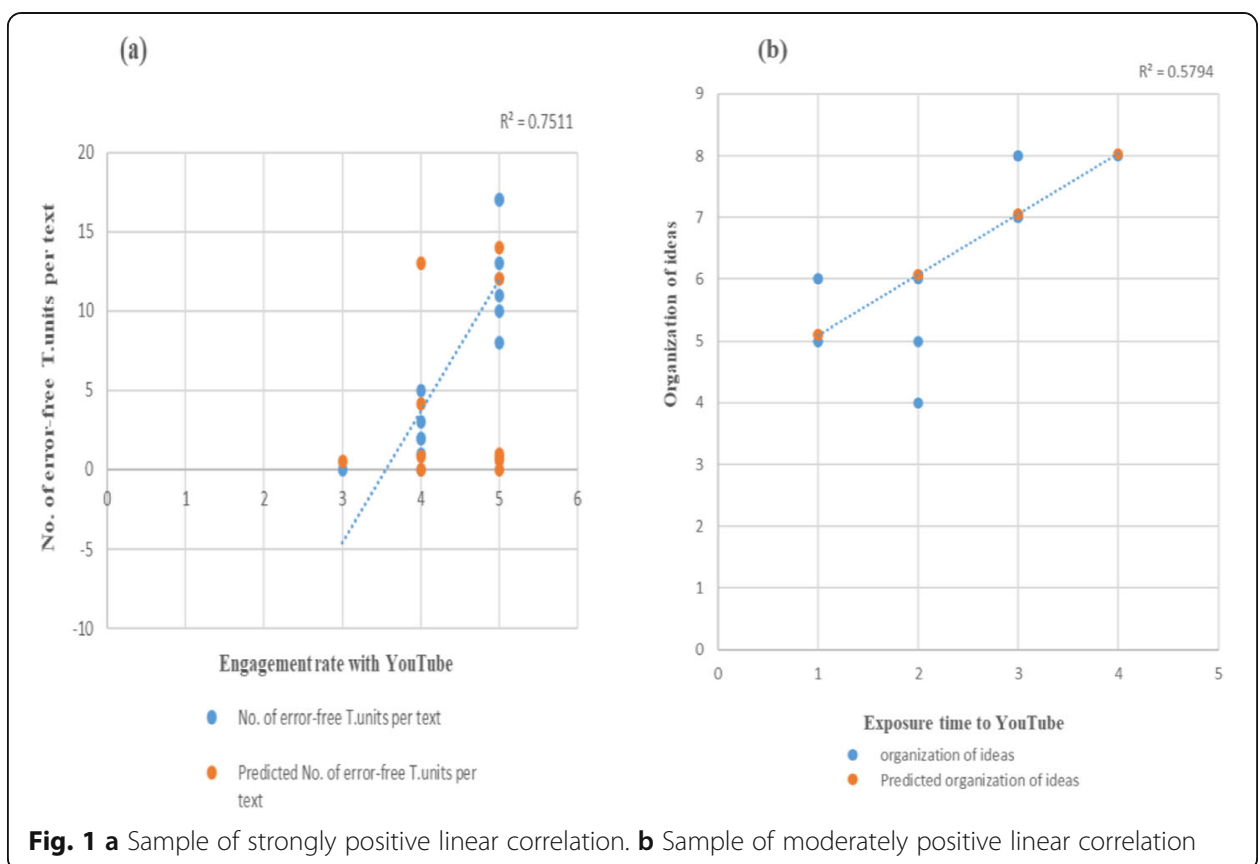

\section{Regression analysis results}

Regression analysis estimated the variation produced by engagement rate with and time range of exposure to YouTube as a source of learning and improving writing on the writing fluency metrics in this study.

The regression analysis results for the engagement rate showed a range of low, moderate and high $\mathrm{R}$ Square values (only the moderate and high values were highlighted in the table below). The moderate $\mathrm{R}$ Squared values were $\left(R^{2}=.367, .358, .536\right)$ and the high values were $\left(R^{2}=.751, .712\right)$. $\mathrm{R}$ squared values represented the proportion of the variance for the respective writing fluency metrics explained by the engagement rate as a predictor. (see Table 6).

Also, most, but not all, of the actual coefficients $p$ values (used to test the null hypothesis where the coefficient is equal to zero i.e., meaning there is no effect while a low $p$ value $<0.05$ indicating that the null hypothesis can be rejected) shown in this table were too small, $p<0.05$. These values also signified a significant linear relationship between the engagement rate with YouTube against their respective writing fluency metrics under study (see Fig. 1. (a)). The Significance F. values (these values

Table 6 Regression analysis for the engagement rate with the suggested YouTube channel

\begin{tabular}{|c|c|c|c|c|c|c|c|}
\hline \multirow[t]{2}{*}{ Regression Analysis } & \multirow{2}{*}{$\begin{array}{l}\mathrm{R} \\
\text { Square }\end{array}$} & \multicolumn{3}{|c|}{ ANOVA } & \multicolumn{3}{|c|}{ Coefficients } \\
\hline & & $\mathrm{df}$ & $\mathrm{F}$ & Sig. & Beta & $\mathrm{t}$ & Sig. \\
\hline Writing rate & 0.367 & 13 & 6.956 & 0.022 & 0.606 & 2.637 & 0.022 \\
\hline No. of error-free T.units per text & 0.751 & 13 & 36.211 & 0.000 & 0.867 & 6.018 & 0.000 \\
\hline Lexical diversity (VOCD) & 0.712 & 13 & 29.682 & 0.000 & 0.844 & 5.448 & 0.000 \\
\hline Lexical density & 0.200 & 13 & 3.008 & 0.108 & -0.448 & -1.734 & 0.108 \\
\hline Mean length of T.unit & 0.167 & 13 & 2.404 & 0.147 & 0.409 & 1.551 & 0.147 \\
\hline Number of clauses per T-unit & 0.358 & 13 & $6 . .688$ & 0.024 & 0.598 & 2.586 & 0.024 \\
\hline Organization of ideas & 0.536 & 13 & 13.866 & 0.003 & 0.732 & 3.724 & 0.003 \\
\hline
\end{tabular}


expressed the results of the F. statistic used to measure the significance of the model and the level of significance) were significant as they were well below the $P<0.05$.

So, it may be suggested with statistically significant $P$ and $R$ Squared values of this regression that the engagement rate with the suggested YouTube channel can variably (moderate-high range) explain between 0.35 to $0.75 \%$ of the fluency improvement in the learners' writing for the corresponding writing fluency variables.

The regression analysis results for the time range of exposure showed a range of low and moderate $R$ Square values (only the moderate values were highlighted in the table below). $\mathrm{R}$ squared values represented the proportion of the variance for the respective writing fluency metrics explained by the exposure time rate as a predictor (see Table 7). Also, most, but not all, of the actual coefficients $p$ values shown in this table were too small, $p<0.05$. These values signified a significant linear relationship between the time range of exposure to YouTube against their respective writing fluency metrics under study (see Fig. 1. (b)). The Significance $F$. values were significant as they were well below the $P<=.05$.

So, it may well be suggested that with statistically significant $P$ and $\mathrm{R}$ Squared values of this regression that the time range of exposure to the suggested YouTube channel can variably (low-moderate range) explain between 0.53 to $0.61 \%$ of the fluency improvement in the learners' writing.

\section{Frequency distributions}

Frequency Distributions were run on data responses of the questionnaire for the following dichotomous (Yes/No) questions (Table 8) to determine the percentages of learners' active use of ICT with regards to its features of personalization, networking and interactivity, inclusiveness and as a resource for rich language input and engaging multi-media materials for learning and improving English writing. Percentages of use for these ICT features can also be found in (Fig. 2).

From the frequency distributions analysis, it can be seen that all of the participants used the YouTube closed captions and its adjustable related settings of font size, colour, opacity and playback speed when learning and improving writing (Question 30 above). (Question 31 above) showed that nearly all the participants shared with other learners interesting YouTube video materials for learning

Table 7 Regression analysis for the time range of exposure to the suggested YouTube channel

\begin{tabular}{|c|c|c|c|c|c|c|c|}
\hline \multirow[t]{2}{*}{ Regression Analysis } & \multirow{2}{*}{$\begin{array}{l}\text { R } \\
\text { Square }\end{array}$} & \multicolumn{3}{|c|}{ ANOVA } & \multicolumn{3}{|c|}{ Coefficients } \\
\hline & & df & $\mathrm{F}$ & Sig. & Beta & $\mathrm{t}$ & Sig. \\
\hline Writing rate & 0.264 & 13 & 4.311 & 0.060 & 0.514 & 2.076 & 0.060 \\
\hline No. of error-free T. units per text & 0.613 & 13 & 18.97 & 0.001 & 0.783 & 4.355 & 0.001 \\
\hline Lexical diversity (VOCD) & 0.539 & 13 & 14.042 & 0.003 & 0.734 & 3.747 & 0.003 \\
\hline Lexical density & 0.181 & 13 & 2.655 & 0.129 & -0.426 & -1.629 & 0.129 \\
\hline Mean length of $\mathrm{T}$. unit & 0.244 & 13 & 3.867 & 0.073 & 0.494 & 1.966 & 0.073 \\
\hline Number of clauses per T-unit & 0.588 & 13 & 17.154 & 0.001 & 0.767 & 4.142 & 0.001 \\
\hline Organization of ideas & 0.579 & 13 & 16.532 & 0.002 & 0.761 & 4.066 & 0.002 \\
\hline
\end{tabular}


Table 8 Frequency Distribution of Items Responses from the questionnaire $(n=14)$

\begin{tabular}{|c|c|c|}
\hline Item & $\begin{array}{l}\text { Frequency } \\
\text { - } \\
\text { Percentage }\end{array}$ & Implication \\
\hline $\begin{array}{l}\text { Q30. Did you use the YouTube closed captions } \\
\text { and its adjustable settings related to font size, } \\
\text { color, opacity and the playback speed for } \\
\text { learning and improving writing? } \\
\text { Yes } \\
\text { No }\end{array}$ & $\begin{array}{l}14-100 \% \\
0-0 \%\end{array}$ & $\begin{array}{l}\text { This suggests that learners leveraged to a great } \\
\text { extent this built-in facility of personalization to } \\
\text { make the input more comprehensible and the } \\
\text { language used more easily and clearly notice- } \\
\text { able and learnable. }\end{array}$ \\
\hline $\begin{array}{l}\text { Q31. Did you often share with other learners } \\
\text { the interesting and useful videos which helped } \\
\text { you in learning writing and learnt from the } \\
\text { interesting videos they or the YouTube itself } \\
\text { suggested you for learning writing? } \\
\text { Yes } \\
\text { No }\end{array}$ & $\begin{array}{l}13-92 \% \\
1-7 \%\end{array}$ & $\begin{array}{l}\text { This suggests a great deal of engagement with } \\
\text { this tool and material for learning, i.e., this is an } \\
\text { example of networking and interactivity. }\end{array}$ \\
\hline $\begin{array}{l}\text { Q32. Did you often use and share what you } \\
\text { have thought and learnt in these YouTube } \\
\text { videos whenever you write in English whether } \\
\text { that is a writing assignment or a comment in } \\
\text { the comments/ live chat section on YouTube? } \\
\text { Yes } \\
\text { No }\end{array}$ & $\begin{array}{l}8-57 \% \\
6-43 \%\end{array}$ & $\begin{array}{l}\text { This shows the actual practice of the target } \\
\text { language skill (i.e., writing) through direct } \\
\text { interaction with other learners and a given } \\
\text { multimedia material using this ICT technology; } \\
\text { this is an instance of inclusiveness \& interactivity. }\end{array}$ \\
\hline $\begin{array}{l}\text { Q33. Did you subscribe and passionately follow } \\
\text { the YouTube channels due to their rich } \\
\text { language input and engaging multi-media ma- } \\
\text { terials for learning and improving your English } \\
\text { writing? } \\
\text { Yes } \\
\text { No }\end{array}$ & $\begin{array}{l}10-71 \% \\
4-29 \%\end{array}$ & $\begin{array}{l}\text { This is an indication that learners found in } \\
\text { YouTube a learning environment due to its rich } \\
\text { language input and engaging multi-media } \\
\text { materials. }\end{array}$ \\
\hline
\end{tabular}

writing and learnt from what others or YouTube itself suggested them for that matter. (Question 32 above) showed that more than half of the participants used what they thought and learnt through these YouTube videos whenever they wrote in English. The majority of the participants did subscribe and passionately follow the YouTube channels due to their rich language input and engaging multi-media materials for learning and improving your English writing (Question 33 above). Taken together, analyzing these frequency distributions indicated that the

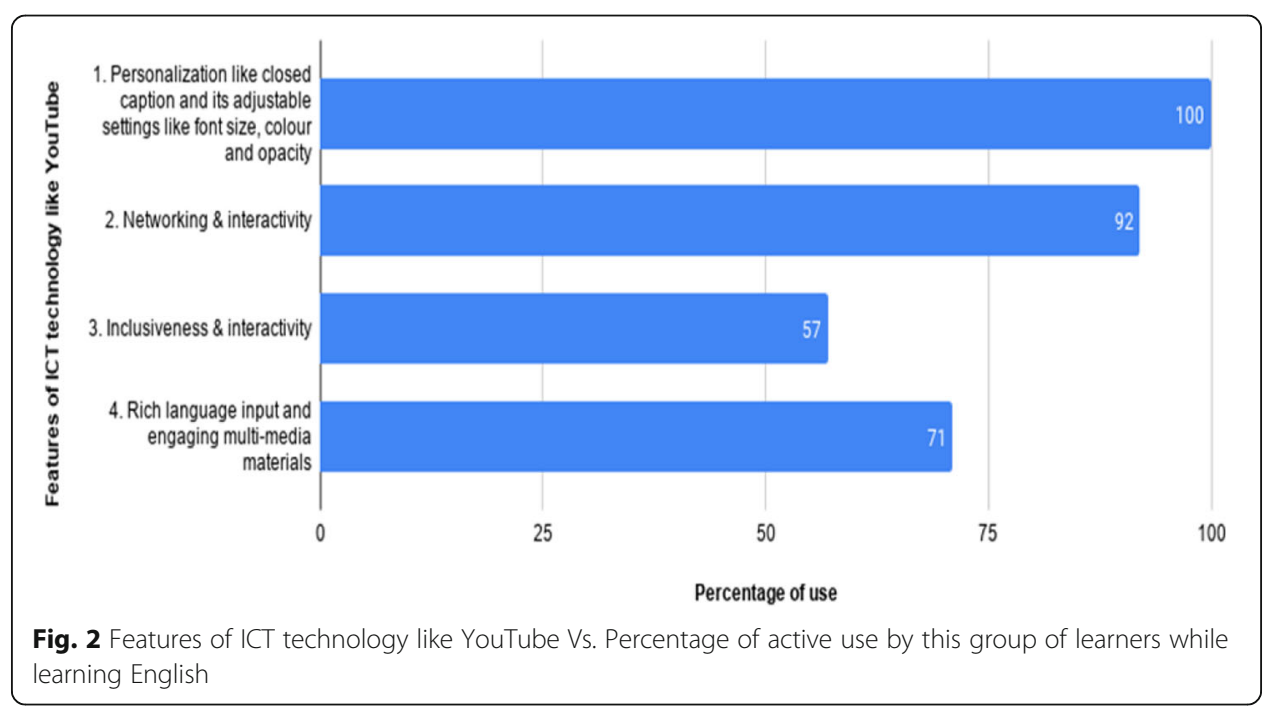


participants actively used ICT tools like YouTube with regards to its features of personalization, networking and interactivity, inclusiveness and as a resource for rich language input and engaging multi-media materials for learning and improving English writing (see Table 8).

\section{Qualitative results}

\section{Content analysis}

In general, the results of this qualitative analysis supported the quantitative findings and brought more information about learners' personal and contextual perspectives on the affordances of YouTube videos and how they thought YouTube videos made learning and improving writing easy and interesting according to their experience. (see Tables 9 and 10). Participants were asked to choose from the answers given to these closed-ended questions what they thought applied to them according to their personal learning experience. The following tables are learners' responses (given in numbers and percentages) in the affirmative for the two-closed questions (Q.34 \& 35) in the questionnaire.

Percentages of participants' responses in this simple content analysis varied over how they thought the affordances of YouTube videos made learning and improving writing easy and interesting. Nevertheless, the majority of participants, in response to each of the above statements (see Tables 9 and 10), thought that the videos aided in different ways in the development and learning of writing. Overall, the participants found that

Table 9 Learners' perspectives on how the affordances of YouTube videos made learning and improving writing easy

\begin{tabular}{|c|c|}
\hline $\begin{array}{l}\text { Q34. How do you think that the affordances of YouTube videos made learning and improving } \\
\text { writing easy for you? }\end{array}$ & $\begin{array}{l}\text { (n) } \% \\
\text { responses }\end{array}$ \\
\hline $\begin{array}{l}\text { the closed caption and its adjustable related settings can make learning writing easier as it can } \\
\text { optimize comprehension of videos content; }\end{array}$ & (15) $100 \%$ \\
\hline $\begin{array}{l}\text { archived and updated learning materials (i.e., this makes it easy to retrieve, check particular } \\
\text { piece of information and learn new things); }\end{array}$ & (11) $71 \%$ \\
\hline $\begin{array}{l}\text { the closed caption helps me correct and improve my vocabulary, grammar, spelling mistakes } \\
\text { and language use through checking my writing with the language used in some video content } \\
\text { (given that this language used is taken as a model especially the natives' language); }\end{array}$ & (14) $92 \%$ \\
\hline $\begin{array}{l}\text { the use of closed caption attracts and focuses the attention and thus facilitate learning/ } \\
\text { noticing aspects related to writing (i.e., grammar, vocabulary, spelling, punctuations); }\end{array}$ & (13) $85 \%$ \\
\hline $\begin{array}{l}\text { simplified, diversified and professional presentation styles through some YouTube channels } \\
\text { make learning writing easy and encourage me to write and interact in writing classes; }\end{array}$ & (13) $85 \%$ \\
\hline autonomy of learning; & (14) $92 \%$ \\
\hline flexible, interactive, interesting and dynamic learning environment; & (11) $71 \%$ \\
\hline community learning; & (13) $85 \%$ \\
\hline easy to learn and develop writing due to the availability of new language input every class; & (14) $92 \%$ \\
\hline $\begin{array}{l}\text { In the comments and live chat section on YouTube, I can write and share what I think with a } \\
\text { huge number of learners around the world without feeling shy down the process; }\end{array}$ & (15) $100 \%$ \\
\hline Easy to understand and expand on ideas/ topics for writing tasks; & (11) $71 \%$ \\
\hline Easy to learn from mistakes and corrections and improve my writing accuracy; & (14) $92 \%$ \\
\hline $\begin{array}{l}\text { Easy for the visual and/or auditory learner (i.e., rich multimodal learning materials like readable, } \\
\text { audible and/ or visual materials) }\end{array}$ & (14) $92 \%$ \\
\hline
\end{tabular}


Table 10 Learners' perspectives on how YouTube affordances made learning and improving writing interesting

\begin{tabular}{|c|c|}
\hline $\begin{array}{l}\text { Q35. How do you think that the affordances of YouTube videos made learning and improving } \\
\text { writing interesting for you? }\end{array}$ & $\begin{array}{l}\text { (n) } \% \\
\text { responses }\end{array}$ \\
\hline $\begin{array}{l}\text { The availability of new, interesting, useful information, language, topics; this is engaging and } \\
\text { makes me more active in writing classes; i.e., food for thought! }\end{array}$ & (14) $92 \%$ \\
\hline $\begin{array}{l}\text { has content that is diversified in terms of language (i.e., formal and informal), topics and others' } \\
\text { cultures; }\end{array}$ & (12) $78 \%$ \\
\hline $\begin{array}{l}\text { supports and provides multimedia learning through materials like readable, audible and/ or } \\
\text { visual materials; }\end{array}$ & (14) $92 \%$ \\
\hline $\begin{array}{l}\text { commenting on other's writings and use their comments/ examples as in the comments/ live } \\
\text { chat sections (i.e., using them in my writing later); }\end{array}$ & (13) $85 \%$ \\
\hline it is attractive and thus supports the visual and/or auditory learner; & (13) $85 \%$ \\
\hline $\begin{array}{l}\text { new and diversified discussions and cultures in the learning materials (i.e., enriching for the } \\
\text { writing experience); }\end{array}$ & (11) $71 \%$ \\
\hline community learning; & (13) $85 \%$ \\
\hline flexible, interactive, interesting and dynamic learning environment; & (14) $92 \%$ \\
\hline compelling and attractive content (i.e., learning materials); & (14) $92 \%$ \\
\hline $\begin{array}{l}m \text { a technophile, i.e., I like the virtual learning environment which includes unlimited number } \\
\text { good teachers with different teaching styles and learners with diverse backgrounds }\end{array}$ & (14) $92 \%$ \\
\hline
\end{tabular}

the affordances of YouTube videos made learning and improving writing easy and interesting with respect to the above listed affordances of YouTube (see Tables 9 and 10).

\section{Discussions}

This study examined the potential role and impact smart of learning environment of ICT tools like YouTube on learners' fluency of language use and expression in their daily written communication. Three main areas related to the main research questions were analysed in this study.

1. the participants' English writing learning experience of both the online and offline English learning resources, including YouTube with regards to their engagement rate with and daily time range of exposure to each of these resources;

2. the participants' actual use of YouTube in particular as an ICT tool for creating the intended smart learning environment with respect to its features of personalization, networking and interactivity, inclusiveness and as a resource for rich language input and engaging multi-media materials for learning and improving English writing; and

3. participants' personal and contextual perspectives on the affordances of YouTube videos and how they thought YouTube videos made learning and improving writing easy and interesting.

Previous research in this area seemingly devoted considerable effort and emphasis on the impact of YouTube usage in the classroom. In this regard, this research has gone a step further by examining the potential impact of such usage on learners' writing fluency in particular. The quantitative findings of the T. Test (Table 1) clearly show some progress in the writing fluency post the integration of YouTube as a tool of language learning over the course of five months for this group of learners. Nonetheless, the $\mathrm{T}$. Test results also show that there is a statistically significant difference only in terms of 
the number of error-free T. units and organization of ideas but not across all the outcome variables which were used as indicators of writing fluency in this work. The findings of this T. Test support previous studies such as those by Pratiwi (2011) and Anggraeni (2012) who reported that YouTube videos help the students to explore main ideas, organize ideas, choose right words to create sentences and paragraphs, produce grammatically correct sentences and use mechanic (punctuation and spelling) in writing. Thus, YouTube is effective in helping the students to better write, quantity and quality-wise, in English.

Furthermore, the results show a clear tendency to both engage and spend more time with the smart learning environment of the online multimedia materials (text and speech) like YouTube to a higher degree and comparatively to a lesser degree with (audio) books, video games, films rather than with online mono-medium materials (text/speech) as it can be seen in the above-Tables 2 and 3). However, there is evidence about learners' offline mono-medium time spent on reading books, including their school syllabus books and assigned readings but with little or no corresponding engagement rate; conversely, learners showed some engagement in offline mono-medium video games but with little or no exposure time (Tables 4 and 5). In other words, multi-media rather than mono-medium materials in the online environment rather than offline, as it is the case in this study, brought by ICT technology like YouTube seem to be all the more engaging (the highest among the group of learning resources) for learners so much so that their learning time using this tool seems to be the highest vis-à-vis time ranges given to other learning resources. In this respect, the results of correlation coefficient (Tables 2 and 3) and regression analyses (Tables 6 and 7) bring in a strong evidence to suggest that the difference in writing fluency performance of this group post the integration of YouTube can clearly be explained by the existing positive linear relationship (Fig. 1a, b) between, on the one hand, the learners' engagement rate with and exposure time to the smart learning environment of YouTube as a source of multimedia language learning input and their fluency improvement in writing, on the other. Such positive linear relationship can be seen more clearly in the case of YouTube media and writing fluency metrics than with any other potential learning resources and writing fluency metrics in this study as indicated by the correlation results (see Tables 2, 3, 4 and 5). These findings are in line with previous studies which found that YouTube usage was linked to students being more engaged, experiencing improved critical thinking ability and greater depth of learning (Clifton \& Mann, 2011).

ICT multimedia learning materials can do a good job for the language learners at different stages of the learning experience as it can not only bring to them an increasing number of authentic language learning materials but also such learning materials can enhance their learning with the ICT capacity of personalization, networking, inclusiveness and engaging and authentic language input. The percentages of ICT features usage by learners (Fig. 2.) suggest that multimedia learning is successfully driving learners to help themselves down the process of language learning through availing the various built-in ICT features and its supplied multi-mediated language input. In this regard, the quantitative findings seen in the frequency distributions (see Table 8) reveal the participants' actual use of YouTube for creating the intended smart learning environment with respect to its features of personalization, networking and interactivity, inclusiveness and as a resource for rich language input and engaging multi-media materials 
for learning and improving English writing. This can reflect the amount of engagement, interaction and enhancement of direct and indirect learning outcomes. In a similar vein, Mayora (2009) focused on the use of YouTube for eliciting improved writing by language learners and also explored how authenticity, interaction, and motivation are inter-twined. He concluded that certain features of YouTube, including the written comments and the possibility for students to express their ideas by constructing meaning through the stimulus of the videos can improve student's writing skills through authentic interaction.

The qualitative responses seen in Tables 9 and 10 demonstrate the positive impact of the affordances of YouTube videos which can aid in different ways in the development and learning of writing, i.e., the affordances of YouTube videos made the process of learning and improving writing easy and interesting. Such affordances of YouTube reflected what has been recently reported in language education (Izquierdo et al., 2015) that ICT makes it easier for learners to access language materials, stressing an existing correlation between second language learning and the use of multi-media materials in a computer-enhanced language learning milieu showing an impact on learning behaviour with increased motivation.

Taken together, the quantitative and qualitative results of this work confirm previous research and indicate that multimedia brought by ICT technology as a source of language learning can be reliably effective for the optimization of language skills including writing as long as some conditions in the learning environment are met, mainly comprehensibility of input, sufficient exposure time devoted by the learner to the learning material and high engagement level with the material rather than the technology itself. (see ; Alvarez-Marinelli et al., 2016; Hung, Huang, \& Hwang, 2014; Kelsen, 2009; Malhiwsky, 2010; Warschauer \& Grimes, 2007).

While learning on YouTube, multimedia learning was actually activated in class and learners were most of the class time observed to be listening attentively to the content of the videos and more importantly fully attracted to the subtitle on the screen which was adjusted size- and colure-wise for explicit signaling effect purposes. Learners did this whenever they had/ were asked to check the right meaning of a particular sentence; they had some doubt/ were asked about an answer to a question in the video or had some inquiry related to language point mentioned in some video like unfamiliar or problematic word meaning/ spelling or grammatical structure). In this regard, based on the basic premise of multimedia learning on the advantage of presentations including signaled text, learners can actively integrate new knowledge into a coherent linguistic and mental model. In other words, linguistic elements need to be linked to some visual stimuli so as to assist learners' storage of the new linguistics elements in their longterm memory; this may indicate how YouTube media help learners' errors (at least to the extent this study findings could demonstrate) move from error to correct. These observations of what the learners' experienced in this study regarding the captioning support and add value to previous studies (Winke et al., 2010) which also mentioned "a number of observations about the use of captions that captions are beneficial because they result in greater depth of processing by focusing attention, reinforce the acquisition of vocabulary through multiple modalities, and allow learners to determine meaning through the unpacking of language chunks". In this respect, learners writing has been improved due to the clarity and comprehensibility of the language input in these 
YouTube videos which could have been assisted through the affordances of ICT multimedia, i.e., enriching for the learners' language as in helping learners write fluently (quantity- as well as quality-wise). (Appendix B) provides two writing samples for two learners showing the kind of improvement in the quality and quantity of writing pre and post the integration of YouTube media for learning and improving writing, like the organisation of ideas and number of errors which have improved besides some new constructions or language chunks that learners seem to have picked from the videos probably by way of chunk learning (it should be mentioned that these chunks were used frequently in these videos). Some examples of these new constructions, which were observed in the learners' writing post the integration of YouTube media, are as well as, I appreciate it, twice a day/week, a day, there's nothing to worry about, as well, even if, again and again, but that doesn't mean, but anyway. What is more, the quantitative findings (Table 1), which have shown the actual participants' writing development, give us some fair idea how some of the learners' disfluencies have become fluent due to the improvement of the above-mentioned writing metrics dealt with in this study.

Even though cognitive advantages of multimedia learning have been widely recognized and adopted by researchers and practitioners across a wide range of disciplines, there is a concurred view among researchers that multimedia may also impede learning and increase cognitive load if not appropriately designed (see Kozma, 1994; Lee, Plass, \& Homer, 2006; Mayer \& Moreno, 2003, as cited in Cook et al., 2008). In this respect, while the captioning might be largely benefiting learners' in certain contexts (see Yoshino et al., 2000; Winke et al., 2010), it could be creating cognitive overload on the learners' working memories at other times as the combination of both speech and text (as it is the case in this experiment) may overwhelm learners' visual channels according to the dual-channel and limited-capacity assumptions of Mayer's cognitive theory of multimedia learning (Mayer, 2009). This study, hence, suggests a trade-off learning/ teaching strategy, i.e., including the captioning when and as much as required so that it doesn't overtax the learners' working memory resources. "Taking this into account, different signalling techniques should be used to gain the learners' attention and reduce extraneous processing when aiming at focusing on specific linguistic aspects in multimedia presentations incorporated into traditionally implemented classroom practices" (Matus, 2018).

Nonetheless, while this study stresses the significance of captioning and its adjustable settings like font size and colour for learning and improving language, many interesting questions related to captioning would immediately arise like if we remove them would we get the same results or otherwise this would change them? Is it the captioning/font/ frequency of use/ length of caption/repetition of caption - are all or any of these important for changing the results? Eye tracking would tell us if students are looking at the captions at all? But then what if they look at the same video more than once, (considering Constant Reverse Navigation Pattern of working memory capacity, Graf, Lin, Kinshuk Chen, \& Yang, 2009) are they still reading the captions? These are particularly relevant and intriguing questions but beyond the scope of this paper and hence deserve the attention and effort in further possible studies.

To conclude with an important statistical note, even though all dependent variables (except for the lexical density variable) set as indicators of fluency in writing have to 
various degrees shown some improvement in writing fluency as indicated by their means differences in the paired-sample T. test results after five months of focused exposure to YouTube, only two of them consistently showed statistically significant results across the three testing and analysis models (refer to T. test, Pearson correlation and Regression analyses results) used in this work; these are the number of error-free T. units per text, reflecting the accuracy dimension of fluency; and the organisation of ideas of learners, reflecting the coherence and cohesion dimension of fluency. However, the other variables (except for the lexical density variable which did show not any improvement) showed improvement but with no statistical significance in this population sample. Therefore, it can be concluded that there is no sufficient evidence to prove that a significant difference exists between the learners' performance before and after the exposure to the suggested ICT tool as far as the fluency in writing is concerned; hence, the null hypothesis $\left(\mathrm{H}_{\mathrm{o}}\right)$ set in this work cannot be entirely rejected nor the alternative hypothesis can be confidently accepted. Such common statistical insignificance and inconsistency on the part of dependent variables may plausibly suggest that more data is needed and further research is required to investigate the issue of writing fluency and to validate the results of this research.

\section{Limitations}

One major challenge was learners' worry about the accuracy over the fluency of their written performance. Therefore, they were reassured that errors are not "signs of inhibition" which need to be eradicated but rather as strategies of learning and as perfectly natural aspects of second language acquisition Corder, S. P. (1967). However, learners would be reminded of the significance of striking a balance between accuracy and fluency in their formal and informal production as these two aspects of writing are closely related that they are inseparable. Another limitation is related to creating learning environments that are adaptive and responsive to specific learners in specific situations is clearly possible, but as the New Media Consortium's 2016 Horizon Report for Higher Education indicates personalized learning is a significant challenge (Adams Becker, Freeman, Giesinger Hall, Cummins, \& Yuhnke, 2016). In this respect, the problem of "one size fits all" when given two or three suggested episodes of the YouTube BBC language show for learners to pick one from to be the crux of the matter for the next class, naturally sometimes few learners would opt for a different topic from what the majority of the class have agreed on to be discussed. In such cases the selected by those few learners but not won by the majority topics would be noted and again re-suggested for other classes to ensure diversified learning materials. Luckily the smart leaning environment could help with such challenges given the multitude of what now became inherent characteristics and advantages of this learning environment and the plethora of increasingly different learning topics and materials for everyone.

\section{Conclusion}

To conclude, this research evidently shows that the smart learning environment of ICT multimedia technology as a source for language learning with its multiple handy features can efficiently drive a range of desired effects for the optimization of writing fluency of language use and expression in the language learners' daily written 
communication. This research, both informed by the its results and other researches in the literature supports the fact that such effects could be effectively driven as long as the essential factors in the learning environment like high engagement, sufficient exposure time, comprehensibility of learning input (on the part of the language learner) and enhancement and intelligibility of learning input (on the part of the environment/ learning materials) are provided by its multi-mediated input, so much so that successful learning is due at any moment. Also, compared to other sources of language learning in the learners' environment, multimedia educational tools developed by ICT like the widely known platform YouTube, being preferred over other learning sources, can be more effective and thus strongly recommended equally for language learners and teachers where optimization of writing fluency is the target of learning. Multimedia materials through ICT technology has made the formal and informal experience of learning more effective and interactive as it is more adjustable, shareable and retainable.

\section{Supplementary information}

Supplementary information accompanies this paper at https://doi.org/10.1186/s40561-020-00134-7.

Additional file 1.

\section{Abbreviations}

ICT: Information and Communication Technology; MMLM: Multi-media Language Materials; BBC: British Broadcasting Corporation; ELT: English Language Teaching; IELTS: International English Language Testing System; $H_{0}$ : Null Hypothesis; $\mathrm{H}_{\mathrm{a}}$ : Alternative Hypothesis; CALL: Computer Assisted Language Learning; Ml: Multi-media Instruction; SNs: Social Networks

\section{Acknowledgments}

This work was completed in collaboration with, and hence special thanks to, the Iraqi School, New Delhi, India. I'm also especially thankful to Mary Alyousef, as a researcher in Linguistics, for her huge language support and advice.

\section{Author's contributions}

I am the sole author of this research work which has been entirely conducted by me as part of my PhD dissertation. The author read and approved the final manuscript.

\section{Author's information}

The author of this paper, (name AA), is a teaching assistant at Al-Furat University since 2011 and currently a third year PhD student at JNU, New Delhi, India. He holds a master's degree in TESOL (2012) and another master's degree in Theoretical Linguistics (2016). He is an educational technologist, and his broad area of interest is technology and multimedia learning.

\section{Funding}

This research is part of an unpublished PhD dissertation at JNU, New Delhi, India and is fully funded by Al-Furat University and the Ministry of Higher Education and Scientific Research, Syria.

Availability of data and materials

The datasets used and/or analysed during the current study are available from the corresponding author on reasonable request.

Ethics approval and consent to participate

Provided.

\section{Consent for publication}

Provided.

Competing interests

The author declares that he has no competing interests.

Received: 18 May 2020 Accepted: 25 August 2020

Published online: 15 September 2020

\section{References}

Adams Becker, S., Freeman, A., Giesinger Hall, C., Cummins, M., \& Yuhnke, B. (2016). NMC/CoSN horizon report: 2016 K-12 edition. Austin: The New Media Consortium.

Ai, H. (n.d.). Web-based L2 Syntactic Complexity Analyzer. https://aihaiyang.com/software/l2sca/. Accessed on 2 Jan 2020. 
Ai, H., \& Lu, X. (2013). A corpus-based comparison of syntactic complexity in NNS and NS university students' writing. In A. Díaz-Negrillo, N. Ballier, \& P. Thompson (Eds.), Automatic treatment and analysis of learner corpus data, (pp. 249-264). Amsterdam/Philadelphia: John Benjamins.

Alvarez-Marinelli, Blanco, M., Lara-Alecio, R., Irby, B.J., Tong, F., Stanley, K., \& Fan, Y. (2016). Computer assisted English language learning in Costa Rican elementary schools: an experimental study, Computer Assisted Language Learning, 29(1), 103-126, https://doi.org/10.1080/09588221.2014.903977.

Analyze My Writing. (n.d.). (Lexical Density Calculator online). http://www.analyzemywriting.com/index.html . Accessed May 2020.

Anggraeni, S.N. (2012). Optimizing the Use of Youtube Video to Improve Students' Competence in Writing Procedure Text (A Classroom Action Research at the Tenth Grade Students of SMA N Kebakkramat in Academic Year of 2011/2012). Sebelas Maret University. Unpublished Thesis.

Annetta, L. A., Minogue, J., Holmes, S. Y., \& Cheng, M. T. (2009). Investigating the impact of video games on high school students' engagement and learning about genetics. Computers in Education, 53, 74-85. https://doi.org/10.1016/j. compedu.2008.12.020.

Aoki, K. (2010). The use of ICT and e-learning in higher education in Japan. World Academy of Science, Engineering and Technology international journal of educational and pedagogical sciences, 4, 6.

Astin, A. (1984). Student involvement: A developmental theory for higher education. Journal of College Student Personnel, 25(4), 297-308 https://www.middlesex.mass.edu/ace/downloads/astininv. Accessed 1 Jan 2020.

Astin, A. W. (1993). What matters in college? Four critical years revisited. San Francisco: Jossey-Bass https://www.researchgate. net/publication/242362064_What_Matters_in_College_Four_Critical_Years_Revisited. Accessed 20 Jan 2020.

Atasoy, A., \& Temizkan, M. (2016). Evaluation of secondary school students' writing fluency skills. Educational Sciences: Theory \& Practice, 16, 1457-1484 https://files.eric.ed.gov/fulltext/EJ1115153. Accessed 2 Jan 2020

Benek-Rivera, J., \& Matthews, V. E. (2004). Active learning with jeopardy: Students ask the questions. Journal of Management Education, 28, 104-118 http://www.upv.es/gie/repositoriolEMA/ek-Rivera\&Mathews2004Active\%20Learning\%20With \%20Jeopardy. Accessed 15 Feb 2020.

Benson, P. (2001). Teaching and researching autonomy in language learning. Harlow: Pearson Education http://www4.pucsp.br/ inpla/benson_artigo. Accessed 14 Feb 2020.

Bertin, J.-C., Grave, P., \& Narcy-Combes, J.P. (2010). Second-language distance learning and teaching: Theoretical perspectives and didactic ergonomics. USA: IGI Global.

British Council. (2020a). https://www.teachingenglish.org.uk/article/comprehensible-input\#sidr-0; Accessed 1 Mar 2020

British Council. (2020b). https://www.teachingenglish.org.uk/article/exposure; Accessed 10 Feb 2020

Brophy, J. (1983). Conceptualizing student motivation. Educational Psychologist Journal, 18, 200-215.

Buchem, l., \& Pérez-Sanagustín, M. (2013). Personal learning environments in smart cities: Current approaches and future scenarios. elearning Papers, 35. http://openeducationeuropa.eu/sites/default/files/asset/In-depth_35_1.pdf.

Chen, P. D., Lambert, A. D., \& Guidry, K. R. (2010). Engaging online learners: The impact of web-based technology on college student engagement. Computers in Education, 54, 1222-1232. https://doi.org/10.1016/j.compedu.2009.11.008

Clifton, A., \& Mann, C. (2011). Can YouTube enhance student nurse learning? NurseEducation Today, 31(4), 311-313. https:// doi.org/10.1016/j.nedt.2010.10.004.

Connell, J. P. (1990). Context, self, and action: A motivational analysis of self-esteem processes across the life-span. In D. Cicchetti (Ed.), The self in transition: From infancy to childhood, (pp. 61-97). Chicago: University of Chicago Press.

Cook, A., Zheng, R., \& Blaz, J. (2008). Measurement of cognitive load during multimedia learning activities. Cognitive Effects of Multimedia Learning., 34-50. https://doi.org/10.4018/978-1-60566-158-2.ch003.

Corder, S. P. (1967). The significance of Learner's errors IRAL 5/1967. 161-170. Accessed 22 Apr 2020.

Dulay, H., M. Burt, and S. Krashen. (1982). Language Two. New York: Oxford University Press.

Ellis, R. (1990). 'Individual styles in classroom second language development' In J. de Jong and D. Stevenson (eds.): Individualizing the Assessment of the Language Abilities. Clevendon, Avon: Multilingual Matters.

Ellis, R. (2002). Second language acquisition. Oxford: Oxford University Press.

Ellis, R., \& Barkhuizen, G. (2005). Analysing learner language. New York: Oxford University Press.

Fellner, T., \& Apple, M. (2009). Developing writing fluency and lexical complexity with blogs. The Jalt Call Journal, 2(1), 15-26.

Ferdouse, F. (2013). Learning from mistakes: Using correction code to improve students writing skill in English composition class. Stamford Journal of English, 7, 62-86. https://doi.org/10.3329/sje.v7i0.14463 Accessed 1 Jan 2020.

Finn, J. D. (1989). Withdrawing from school. Review of Educational Research, 59, 117-142.

Global eSchools and Community Initiative (GeSCl). (2007). Concept note: Developing a model for inclusive education and assistive technology appropriate for teaching and learning contexts in developing countries. Available at http://www. gesci.org/old/files/docman/model_ie_at.pdf.

Graf, S., Lin, T., Kinshuk Chen, N. S., \& Yang, S. J. H. (2009). Learning styles and cognitive traits_-Their relationship and its benefits in web-based educational systems. Computers in Human Behavior, 25(6), 1280-1289.

Grzeszczyk, K. B. (2016). Using multimedia in the English language classroom Kamila Barbara http://www.worldscientificnews. com/wp-content/uploads/2015/10/WSN-433-2016-104-1571. Accessed 20 Apr 2020

Gurbin, T. (2015). Metacognition and technology adoption: Exploring influences. Procedia - Social and Behavioral Sciences, 191, $1576-1582$.

Hung, C., Huang, I., \& Hwang, G. (2014). Effects of digital game-based learning on students' self-efficacy, motivation, anxiety, and achievements in learning mathematics. Journal of Computer Education, 1, 151-166. https://doi.org/10.1007/s40692014-0008-8.

Izquierdo, J., Simard, D., \& Garza, M. G. (2015). Multimedia instruction \& language learning attitudes: A study with university students. Revista Electrónica de Investigación Educativa, 17(2), 101-115 http://redie.uabc.mx/vol17no2/contents-izqsimard. html. Accessed 30 Mar 2020.

Junco, R. (2012). The relationship between frequency of Facebook use, participation in Facebook activities, and student engagement. Computers \& Education, 58, 162-171. https://doi.org/10.1016/j.compedu.2011.08.004.

Kelsen, B. (2009). Teaching EFL to the iGeneration: A survey of using YouTube as supplementary material with college EFL students in Taiwan. CALL-EJ., 10. 
Koo, T. K., \& Li, M. Y. (2016). A guideline of selecting and reporting Intraclass correlation coefficients for reliability research. Journal of Chiropractic Medicine, 15(2), 155-163 https://www.ncbi.nlm.nih.gov/pmc/articles/PMC4913118/ Accessed 3 Apr 2020 .

Kozma, R. B. (1994). Will media influence learn-ing? Reframing the debate. Educational Technol-ogy Research \& Development, 42, 7-19.

Kramsch, C. (1999). Teaching text and context through multimedia. Language, Learning and Technology, 2(2), 31-41 https:// scholarspace.manoa.hawaii.edu/bitstream/10125/25041/1/02_02_article1. Accessed 22 Apr 2020.

Krashen, S. D. (1985). The input hypothesis: Issues and implications. New York: Longman.

Krashen, S. D., Long, M. A., \& Scarcella, R. C. (1979). Age, rate, and eventual attainment in second language acquisition. TESOL Quarterly, 13, 573-582 https://www.academia.edu/40603904/Age_Rate_and_Eventual_Attainment_in_Second_Language_ Acquisition. Accessed 8 Mar 2020.

Kunschak, C. (2004). Language Variation in Foreign Language Teaching: On the Road to Communicative Competence. Frankfurt/ Main: Peter Lang Publishing.

Kyle, K. (2016). Measuring syntactic development in L2 writing: Fine grained indices of syntactic complexity and usage-based indices of syntactic sophistication (Doctoral Dissertation). Retrieved from http://scholarworks.gsu.edu/alesl_diss/35.

Lee. H., Plass, J. L., \& Homer, B. D. (2006). Optimizing cognitive load for learning from computer-based science simulations. Journal of Educational Psychology, 98(4), 902-913. (2) (PDF) Measurement of cognitive load during multimedia learning activities. Available from: https://www.researchgate.net/publication/288581585_Measurement_of_cognitive_load_during_ multimedia_learning_activities.

Libbrecht, P., Müller, W., \& Rebholz, S. (2015). Smart learner support through semi-automatic feedback. https://doi.org/10.1007/ 978-3-662-44447-4 8.

Long, M. H. (1983). Native speaker/ non-native speaker conversation and the negotiation of comprehensible input. Applied Linguistics, 4, 126-141 https://core.ac.uk/download/pdf/32302617. Accessed 24 Jan 2020.

Long, M. H. (1985). Input and second language acquisition theory. In S. M. Gass, \& C. G. Madden (Eds.), Input in second language acquisition, (pp. 377-393). Rowley: Newbury House.

Lu, X. (2010). Automatic analysis of syntactic complexity in second language writing. International Journal of Corpus Linguistics, 15(4), 474-496.

Lu, X. (2011). A corpus-based evaluation of syntactic complexity measures as indices of college-level ESL writers's language development. TESOL Quarterly, 45(1), 36-62.

$L u, X ., \& A i, H$. (2015). Syntactic complexity in college-level English writing: Differences among writers with diverse $L 1$ backgrounds. Journal of Second Language Writing, 29, 16-27.

Malhiwsky, D. (2010). Student achievement using web 2.0 technologies: A mixed methods study.

Matus, F. (2018). Effects of the Signalling principle on EFL learning: A study of explicit presentation of frequent grammar mistakes using an adapted functional teaching approach. Athens Journal of Philology, 5, 97-120. https://doi.org/10.30958/ajp.5-2-2.

Mayer, R. (2005). Multimedia learning: GuidingVisuospatial thinking with instructional animation. In P. Shah, \& A. Miyake (Eds.), The Cambridge handbook of visuospatial thinking, (pp. 477-508). Cambridge: Cambridge University Press.

Mayer, R. E. (2002). Multimedia learning https://www.sciencedirect.com/science/article/pii/S0079742102800056. Accessed 23 Feb 2020.

Mayer, R. E. (2009). Multimedia learning. New York: Cambridge University Press.

Mayer, R. E., \& Moreno, R. (2003). Nine ways to reduce cognitive load in multimedia learning. Educational Psychologist, 38(1), $43-52$.

Mayora, C. A. (2009). Using YouTube to encourage authentic writing in EFL classrooms. TESL Reporter, 42(1), 1-12.

McKay, S. L. (2002). Teaching English as an International Language: Rethinking Goals and Approaches. Oxford: Oxford University Press.

Mikulecký, P. (2012). Smart environments for smart learning. In Proceedings of DIVAl 2012-9th International Scientific Conference on Distance Learning in Applied Informatics (pp. 213-222).

Mitterer, H., \& McQueen, J. M. (2009). Foreign subtitles help but native-language subtitles harm foreign speech perception. PLoS One, 4(11), e7785. https://doi.org/10.1371/journal.pone.0007785 Accessed 2 Feb 2020.

Mukhaini, E., Al-Qayoudhi, W., \& Al-Badi, A. (2014). The adoption of social networking in education: A study of the use of social networks by higher education students in Oman. Journal of International Education Research https://clutejournals. com/index.php/JIER/article/view/8516/8523. Accessed 6 Mar 2020.

Natriello, G. (1984). Problems in the evaluation of students and student disengagement from secondary schools. Journal of Research and Development in Education, 17, 14-24.

Oshima, A., \& Hogue, A. (1997). Introduction to academic writing. Addison Wesley: Longman.

Pannell, J., Partsch, F., \& Fullver, N. (2017). The output hypothesis: From theory to practice. TESOL working paper series, 15, (pp. 126-159) https://www.hpu.edu/research-publications/tesol-working-papers/2017/2017-new-with-metadata/06 pannellpartschfuller output. Accessed 10 Apr 2020.

Patera, M., Draper, S., \& Naef, M. (2008). Exploring magic cottage: A virtual reality environment for stimulating children's imaginative writing. Interactive Learning Environments, 16, 245-263. https://doi.org/10.1080/10494820802114093 Accessed 4 Feb 2020

Peregoy, S. F., \& Boyle, O. F. (2005). Reading, writing, and learning in ESL: A resource book for K12 teachers Pearson/Ally \& Bacon.

Plass, J. L., \& Jones, L. C. (2005). Multimedia learning in second language acquisition. In R. E. Mayer (Ed.), The Cambridge handbook of multimedia learning (pp. 467-488). New York: Cambridge University Press.

Pratiwi, A.I. (2011). Optimizing the Use of Youtube Video to Improve Students' Writing Skill (A Classroom Action Research at the Second Grade of SMP Negeri 1 Juwirang Klaten in the academic Year of 2009/2010). Sebelas Maret University. Unpublished Thesis.

Pun, M. (2013). The use of multimedia technology in English language teaching: A global perspective. Crossing the border: International journal of interdisciplinary studies, 1 ISSN 2350-8752(P) volume. https://www.nepjol.info/index.php/CTBIJIS/ article/view/10466. Accessed 10 Apr 2020.

Rice, D. (2011). Appendix 1: Use of ICTs for inclusive education http://inova.snv.jussieu.fr/evenements/colloques/colloques/ article.php?c=70\&l=en\&a=361. Accessed 15 Mar 2020. 
Robinson, J. (2019). Asian English - the British library https://www.bl.uk/british-accents-and-dialects/articles/asian-english. Accessed 15 Feb 2020.

Sarason, Y., \& Banbury, C. (2004). Active learning facilitated by using a game-show format or who doesn't. Journal of Management Education, 28(4), 509-518 https://eric.ed.gov/?id=EJ797827. Accessed 9 Feb 2020.

Schmidt, R. (1990). The Role of Consciousness in Second Language Learning. Applied Linguistics 11, 129-158.

Schmidt, R. (2001). Attention. In P. Robinson (Ed.), Cognition and second language instruction (pp. 3-32). Cambridge: Cambridge University Press.

Schmidt, R. (2010). Attention, awareness, and individual differences in language learning. Singapore: National University of Singapore, Centre for Language Studies http://nflrchawaii.edu/PDFs/SCHMIDT\%20Attention,\%20awareness,\%20and\%2 Oindividual\%20differences. Accessed 10 Jan 2020.

Smith, M. (1991). Speaking to many minds: On the relevance of different types of language information for the L2 learner. Second Language Research, 7(2), 118-132 www.jstor.org/stable/43104426. Accessed 19 Feb 2020.

Swain, M. (2005). The output hypothesis: theory and research. In E. Hinkel (Ed.), Handbook of research in second language teaching and learning (pp. 471-483). Yahweh, N.J: Lawernce EelbaumAssociates.

Swain, M., \& Lapkin, S. (1995). Problems in output and the cognitive processes they generate: A step towards second language learning https:/academic.oup.com/applij/article-abstract/16/3/371/184113?redirectedFrom=fulltext. Accessed 15 Mar 2020.

Tarantino, K., McDonough, J., \& Hua, M. (2013). Effects of student engagement with social media on student learning: A review of literature https://www.researchgate.net/publication/280079702_Effects_of_student_engagement_with_social_media_on_ student_learning_A_review_of_literature. Accessed 142020.

Text Inspector. (n.d.) (A tool used for measuring lexical diversity using the computations of MTLD and VOCD). https://textinspector.com/

UNESCO 2008 "UNESCO 48th International Conference on Education - Reference document" available at http://www.ibe. unesco.org/fileadmin/user_upload/Policy_Dialogue/48th_ICE/CONFINTED_48-3_English.pdf.

Vaezi, S., \& Kafshgar, N. B. (2012). Learner characteristics and syntactic and lexical complexity of written products. International Journal of Linguistics, 4(3), 671-687.

Van Gelderen, A., \& Oostdam, R. (2005). Effects of fluency training on the application of linguistic operations in writing. Educational Studies in Language and Literature, 5(2), 215-240.

Vaughan, T. (1993). Multimedia: Making it work, (1st ed., ). Osborne, Berkeley: McGraw-Hill.

Warschauer, M., \& Meskill, C. (2000). Technology and Second Language Teaching. Handbook of Undergraduate Second Language Education. New Jersey: Lawrence Erilbaum.

Warschauer, M., \& Grimes, D. (2007). Audience, authorship, and artifact: The emergent semiotics of web 2.0. Annual Review of Applied Linguistics, 27, 1-23.

Winke, P., Gass, S., \& Sydorenko, T. (2010). The effects of captioning videos used for foreign language listening activities Michigan State University. Language Learning \& Technology. https://scholarspace.manoa.hawaii.edu/bitstream/10125/44203/1/14_ 01 winkegasssydorenko. Accessed 22 Jan 2020

Wolfe-Quintero, K., Inagaki, S., \& Kim, H. Y. (1998). Second language development in writing: Measures of fluency, accuracy and complexity. Technical report 17. Manoa: University of Hawai'i Press.

Xiao, M. (2007). An empirical study of using internet-based desk videoconferencing in an EFL setting. Ohio: The College of Education of Ohio University https://etd.ohiolink.edu/pg_10?0::NO:10:P10_ACCESSION_NUM:ohiou1194703859. Accessed 5 Jan 2020.

Yang, W. (2008). Optimization of multimedia English teaching in context creation. International Education Studies, 1, 4 https://files.eric.ed.gov/fulltext/EJ1065458. Accessed 5 Apr 2020.

Yesner, R. (2012). The next-generation classroom: smart, interactive and connected learning environments. IDC Government Insights.

Yoshino, S., Kano, N., \& Akahori, K. (2000). The effects of English and Japanese captions on the listening comprehension of Japanese EFL students. Language Laboratory, 37, 111-130. Tokyo Institute of Technology.

\section{Publisher's Note}

Springer Nature remains neutral with regard to jurisdictional claims in published maps and institutional affiliations.

\section{Submit your manuscript to a SpringerOpen ${ }^{\circ}$ journal and benefit from:}

- Convenient online submission

- Rigorous peer review

- Open access: articles freely available online

- High visibility within the field

Retaining the copyright to your article

Submit your next manuscript at $\boldsymbol{\nabla}$ springeropen.com 